\title{
Straight talk from... Eva Harris
}

Since the late 1980s, the San Francisco-based Sustainable Sciences Institute has made it its mission to train scientists in resource-poor countries and help them cobble together low-cost devices_to "give people the tools they need and let them run with them," as its ebullient leader Eva Harris says. Among the institute's most famous inventions, for example, are a centrifuge made from a blender and a no-frills PCR method that uses homemade thermal cycling equipment and ceramic dust instead of silica for purifying the DNA. A 1997 MacArthur fellowship allowed Harris to expand the institute from an informal setup to a more official organization. Since then, with an annual budget of about \$1 million that is coaxed from foundations and rom individual donors, the institute has held more than 30 workshops, training mainly Latin American scientists in topics ranging from diagnostics to epidemiology to grant writing. The institute also gives out mini-grants to the most promising projects. Here Harris talks about the philosophy behind the institute's unique approach, its successes, its many ongoing projects and the eternal struggle for funding.

What distinguishes the institute from other efforts to boost research capacity worldwide?

A lot of successful efforts involve researchers with a US grant finding partners in developing countries. But those efforts are often driven by the first-world scientists and agendas. We listen first to the priorities of the scientists who are asking for our assistance. And that often takes longer than if the 'North' just drives the agenda. We also always have instructors from one country who we have already trained as our instructors for the next workshop in another country in the region.

One scientist who took our workshops, Nataniel Mamani at the Universidad Mayor de San Andrés in La Paz, Bolivia, created a course on how to make your own lab equipment. We have been doing a bit less of that kind of tinkering lately, but what I think is really important is the philosophical concept that all of these techniques are doable if you understand the fundamental principles. We have broadened our approach to helping people set up a lab with what they have and what we can help them get.

\section{How do you choose where to work?}

We would probably be bigger if we didn't focus on countries or parts of countries with little infrastructure. But we have been very dogged about staying with that mission. It is very much about responding to needs. Other people work on creating new technologies and methods; we are concerned with getting what exists out there.

If you do that, you sometimes get a wonderful kind of leapfrogging. In Nicaragua, we are following 3,800 kids over six years in a dengue study. In the beginning, we thought maybe we would put photographs on the identification cards. Within eight months, our Nicaraguan team suggested barcodes on the ID cards, and then, within two months, they had transformed the whole study to work using barcodes, fingerprint scanning, global positioning systems and hand-held computers. Their approach has expanded to other parts of the healthcare system such as vaccination efficiency and prenatal care. It was completely not what I had been thinking. I am surprised every time.

\section{What kind of projects do you tend to fund?}

It has morphed over the years, but we have always tried to support research with a public health focus. Much of it is basic lab setup and training. We work with diagnostics and reference and research labs within the context of the priority diseases of the country.

For example, in Paraguay there was a huge dengue epidemic in 1999 and 2000. Local scientists came to us and we set up a partnership with the university and the ministry of health. We brought them equipment and supplies. I trained one of their people here, and then we went down and did several workshops. They were able to do active surveillance and pick up outbreaks from areas around the bus station from Brazil before they spread. But then came political changes which removed the people we trained, and there was a bad dengue outbreak there more recently.
What is the greatest hurdle you face?

Our focus on people is our Achilles heel. Our institute is in the nonprofit sector, and our work should be allowed to be about people. But most foundations are not really interested in training people. They want gadgets, they want research, they want projects. People love our model, and yet it is hard to fund. Metrics are rather difficult in training. It is not as easy as if we distributed 40,000 of this or that. And it is actually more profound than that. We are empowering our partners in developing countries and instilling them with confidence.

What do you feel is your biggest failure?

People tell me I am a dynamic speaker, but I am not a business type. I am probably not selling the institute the right way. I've talked to people from the Bill \& Melinda Gates Foundation, and several times they were sending the check and then they reorganized. It makes me uncomfortable to sell; it rubs me the wrong way. I don't like to sully this beautiful stuff with money.

\section{What drew you to this kind of work?}

I grew up between New York and Paris in a progressive household. I am an only child and I was very influenced by my parents' friends, many of them European socialists. And I always was interested in biology. So I wanted to share my educational privilege with people less fortunate. I wanted to go to the developing world, but I didn't want to go as a tourist. At that time, Nicaragua was in the middle of the revolution, and they were accepting technical specialists as volunteers. This was in the Reagan ' 80 s, and I was very unhappy with foreign policy and the Contra war. I was unhappy with what was being done overtly and covertly in our name and felt it should be possible to work internationally in a positive way.

In Nicaragua, there was running water maybe twice a week and roosters running everywhere, and 100-degree heat every day in the middle of an economic blockade. But together with my Nicaraguan colleagues, I created a series of workshops by listening to what they needed. They had a problem with leishmaniasis, and they wanted to learn molecular biology. Through the workshops, I was able to teach them PCR right after it was invented, and it was the first time anyone in the country had seen DNA. We were able to diagnose leishmaniasis rapidly, determine the species of the parasite and develop diagnostic tools that were implemented immediately at the national level. I realized that the key to this kind of work is to understand the principles and partner with people in an equitable, respectful and long-term manner. We are still there.

Emma Marris, Columbia, Missouri 